\title{
THE INTERAGENCY FUELS TREATMENT DECISION SUPPORT SYSTEM: FUNCTIONALITY FOR FUELS TREATMENT PLANNING
}

\author{
Stacy A. Drury ${ }^{*}$, H. Michael Rauscher ${ }^{2}$, Erin M. Banwell ${ }^{1,3}$, ShihMing Huang ${ }^{1}$, \\ and Tami L. Lavezzo ${ }^{1}$ \\ ${ }^{1}$ Sonoma Technology, Inc., \\ 1455 N. McDowell Boulevard, Suite D, Petaluma, California 94954, USA \\ ${ }^{2}$ Rauscher Enterprises, LLC, \\ 1733 Old NC 20, Leicester, North Carolina 28748 , USA \\ ${ }^{3}$ Bureau of Land Management, Roseburg District, \\ 777 Garden Valley Boulevard, Roseburg, Oregon 97471, USA \\ *Corresponding author: Tel.: +1-707-665-9900; e-mail: sdrury@sonomatech.com

\section{ABSTRACT} \\ RESUMEN
}

The Interagency Fuels Treatment Decision Support System (IFTDSS) is a web-based software and data integration framework that organizes fire and fuels software applications into a single online application. IFTDSS is designed to make fuels treatment planning and analysis more efficient and effective. In IFTDSS, users can simulate fire behavior and fire effects using the scientific algorithms and processes found in desktop applications including FlamMap, Behave, FOFEM, and Consume. Strategic-level goals of IFTDSS are to

- $\quad$ simplify the fuels treatment planning decision-support process;

- improve the overall quality of analysis and planning;

- control long-term costs;

- encourage scientific collaboration;

- reduce agency information technology (IT) workload in
El Sistema de Soporte para la Decisión del Tratamiento de los Combustibles (IFTDSS por su sigla en inglés) es un software basado en Internet y en un marco de integración de datos que organiza aplicaciones de software de fuego y combustibles en una sola aplicación online. IFTDSS está diseñada para hacer planificaciones y análisis de tratamientos de combustibles más eficientes y efectivas. En IFTDSS, los usuarios pueden simular el comportamiento del fuego y los efectos del fuego utilizando algoritmos científicos y procesos encontrados en aplicaciones de escritorio incluyendo FlamMap, Behave, FOFEM y Consume. Los objetivos a nivel estratégico de IFTDSS son:

- simplificar el proceso de apoyo en las decisiones de planificación del tratamiento de combustibles;

- mejorar la calidad general de análisis y planificación;

- controlar los costos de largo plazo;

- alentar la colaboración científica;

- reducir la carga de información tecnológica de la agencia (IT) en el des- 
deploying and maintaining fuels applications and data; and

- promote interagency collaboration within the fire and fuels community.

This paper discusses the tools and processes IFTDSS offers to fire, fuels, and resource managers responsible for planning fuels treatment within a framework of hazard analysis and risk assessment. We outline how fire and fuels treatment planners can use IFTDSS to identify areas of high hazard and risk, evaluate the potential burning risk and hazard level for valued resources (values at risk) within the area of interest, and simulate the effectiveness of fuels treatments in reducing the potential harm to values at risk. pliegue y mantenimiento de aplicaciones y datos de combustible; y

- promover la colaboración entre agencias dentro de la comunidad de fuego y combustibles.

Este trabajo discute las herramientas y los procesos que IFTDSS ofrece al fuego, a los combustibles y a los gestores de recursos responsables en la planificación de tratamiento de combustibles dentro de un marco de análisis del peligro y determinación del riesgo. Nosotros delineamos cómo los planificadores de fuego y combustibles pueden usar IFTDSS para identificar áreas de alto peligro y riesgo, evaluar el riesgo de quema potencial y el nivel de peligro para recursos de valor (valores en riesgo) dentro del área de interés, y simular la efectividad del tratamiento de los combustibles al reducir el daño potencial de los valores en riesgo.

Keywords: fire behavior modeling, fire effects modeling, fuels planning, fuels treatment, hazard assessment, IFTDSS, prescribed burning, risk assessment

Citation: Drury, S.A., H.M. Rauscher, E.M. Banwell, S.M. Huang, and T.L. Lavezzo. 2015. The Interagency Fuels Treatment Decision Support System: functionality for fuels treatment planning. Fire Ecology 12(1): 103-123. doi: 10.4996/fireecology.1201103

\section{INTRODUCTION}

\section{Why Create a Fuels Treatment Decision Support System?}

From the national to the local level, there is a clear mandate to reduce hazardous fuel loadings within the continental United States, Alaska, and Hawaii. This mandate is primarily driven by the dramatic increase in the number of large wildfires throughout the western United States during recent decades (Westerling et al. 2006, Dennison et al. 2014). These more frequent large fires may also be more severe due to increases in fuel loadings and hotter, drier climates (Miller et al. 2009; van Mantgem et al. 2013). As these large wildfires have become more common, people have also been moving into areas susceptible to wildfire, thereby increasing the risk to human life and property (Radeloff et al. 2005, Berry et al. 2006, Blanchard and Ryan 2007). In response to the increased risk of wildfires to humans, federal agencies have increased their emphasis on using fuels treatments to reduce the amount of fuels available to burn during wildfires (US Government Accounting Office 1999, 2002, 2003, 2004). The primary objective of most fuels treatments is to lower fire behavior potentials and fire effects during subsequent wildfires (Reinhardt et al. 2008). The logic underlying fuels treatments is that fire behavior depends on three variables known as the classic fire behavior triangle: topography, weather, and fuels (Countryman 2004). Land managers cannot change topography or control 
weather, but they can influence the quantity, continuity, and compactness of fuels available to burn by using mechanical or prescribed burning techniques to treat those fuels (Reinhardt et al. 2008).

Landscape restoration is also often a major objective when planning and implementing fuels treatments (Agee and Skinner 2005, Reinhardt et al. 2008). Many fuels treatments are designed to restore an ecosystem to a former state, with the major goal of making the ecosystem more fire resilient so that subsequent fire behavior is less severe and future fires burn in a more natural state (Fulé et al. 2012).

In response to the desire to implement fuels treatments at multiple scales, and to simulate the potential influence of fuels treatments on post-treatment fire behavior and fire effects, many software tools for simulating fire behavior and fire effects have been produced. The funding for these software tools and systems was provided with little coordination, minimal control, and little overall vision, leading to what has been called a software "chaos" with respect to modeling fire behavior and fire effects within the fuels treatment context (Funk 2009, Rauscher et al. 2013). Moreover, a governance process for transitioning a research-grade software application to an operationally ready one was never created (Bennett et al. 2013). The result is a fuels management environment with numerous, fragmented, stand-alone tools; system and data access issues; decentralized planning and support; minimal security; and ad hoc training.

In recognition of the software chaos problem, the Joint Fire Science Program (JFSP) and its partners - the National Wildfire Coordinating Group (NWCG) Fuels Management Committee (formerly the National Interagency Fuels Coordinating Group) - initiated the Software Tools and Systems (STS) study in 2007 (www.frames.gov/iftdss). The STS study identified fuels treatment analysis and planning as the most pressing problem defined by field users and produced a document de- scribing the functionality required in a fuels treatment decision support system (Funk 2009). The STS study described the tools and data products required to meet fuels treatment planning needs and laid out these needs as a set of tasks that fuels specialists commonly accomplish when planning fuels treatments. In short, field users identified what they needed to be able to do, and how they wanted to be able to do it. Users wanted an end-to-end process, along with plenty of choices on how to perform the intermediate steps. To meet these needs, we created the workflow concept within IFTDSS to support fuels treatment planning within the United States. Each workflow is a step-by-step process that provides users with a pathway for completing the tasks defined in the STS study.

Version 2.0 of IFTDSS is a beta release that is being developed and managed by the Interagency Wildland Fire Management Research, Development, and Applications Team with a fully operational alpha version planned for release in 2017. IFTDSS uses data, tools, models, and processes applicable to, and developed for, fire modeling in the United States. No models or tools developed internationally are currently housed in IFTDSS, but applications developed outside the United States may be implemented in future versions of IFTDSS when the need and desire to use these tools within the United States arises.

In this paper, we focused on what IFTDSS offers to the target users: fire, fuels, and resource managers tasked with planning fuels treatment within a hazard and risk assessment framework. Our objectives were to outline how IFTDSS enables fuels treatment planners to 1) identify areas of high hazard and risk within an area of interest, 2) evaluate the potential risk of burning and the potential hazard if valued resources (values at risk) burn, and 3) simulate how fuels treatments can lower the potential harm to values at risk due to burning. 


\section{DISCUSSION}

\section{Design and Implementation of IFTDSS}

Throughout the development of IFTDSS, fire, fuels, and resource managers have actively participated in designing and determining the functionality in IFTDSS. Well over 100 fire and fuels specialists have provided direct and indirect feedback to identify the most pressing modeling needs for planning fuels treatments. Feedback was provided in multiple forums including webinars, workshops, face-to-face meetings, individual interviews, and a feedback link in IFTDSS (http://iftdss. sonomatech.com). All user feedback received is documented and linked in a feedback tracking database so that, as development is planned, new functionality based on user demand is added.

\section{How Can Fire, Fuels, and Resource Managers Use IFTDSS?}

IFTDSS provides access to the software tools (Table 1) typically used to simulate fire behavior and fire effects within a common user interface. While generally referred to as models by fire managers, software tools for modeling wildland fire such as BehavePlus 5.0 (Heinsch and Andrews 2010), Consume 4.0 (Prichard et al. 2006), and the First Order Fire Effects Model (FOFEM; Reinhardt et al. 1997) are actually a collection of fire behavior and fire effects models collected within desktop software applications. In fact, Andrews (2013) explained that BehavePlus 5.0 is a collection of more than 40 individual fire behavior, tree mortality, and weather models. Each of these software modeling applications can be downloaded individually from the developers' websites and loaded onto individual users' computer systems. IFTDSS removes the need for an individual user to acquire and install desktop software applications, as the tools are provided in a single online location. The pro- cessing power of many different modeling systems is brought together in one place. Furthermore, IFTDSS can reduce training and re-familiarization time because the user no longer needs to learn how to use multiple tools with different interfaces. Users also save time because they no longer need to transform data from one software system to another. IFTDSS transforms an incompatible set of stand-alone, stove-piped software applications into a consolidated, manageable, single software application.

IFTDSS provides access to fire behavior and fire effects tools through a logical stepwise pathway referred to as a workflow. IFTDSS workflows have evolved into a set of business-oriented modeling pathways intended to capture the fuels treatment planning needs of fire, fuels, and resource managers. Workflows are designed to lead users step-by-step through the process of modeling fuels treatments. Five workflows have been identified and implemented in IFTDSS Version 2.0:

1. The Data Acquisition and Editing Workflow is used to identify the appropriate vegetation, geophysical, and weather data for IFTDSS that will be needed for a project. IFTDSS goes to authoritative data sets, such as LANDFIRE, and automatically downloads the requested data coverage. Users may then view and edit the data acquired in order to customize it for a project analysis. The customized data set(s) may then be saved, output in selected file formats to a local computer, and shared with other IFTDSS users.

2. The Hazard Analysis Workflow is used to identify potentially hazardous areas across a landscape. The focus of this workflow is to identify areas across a landscape where potential fire hazard is high and fuels treatment analysis may be warranted. 
Table 1. Models and associated algorithms used in IFTDSS.

\begin{tabular}{|c|c|}
\hline Model & Description \\
\hline BehavePlus & $\begin{array}{l}\text { The BehavePlus fire modeling system is a collection of models that describes fire } \\
\text { behavior, fire effects, and the fire environment. } \\
\text { www.firelab.org/project/behaveplus }\end{array}$ \\
\hline Consume & $\begin{array}{l}\text { Consume } 3.0 \text { is designed to import data directly from the Fuel Characteristic } \\
\text { Classification System (FCCS), and the output is formatted to feed other models and } \\
\text { provide usable outputs for burn plan preparation and smoke management requirements. } \\
\text { Training and a user's manual are available. Consume can be used for most forest, } \\
\text { shrub, and grasslands in North America. } \\
\text { www.fs.fed.us/pnw/fera/research/smoke/consume/index.shtml }\end{array}$ \\
\hline FCCS & $\begin{array}{l}\text { The Fuel Characteristic Classification System (FCCS) offers consistently organized } \\
\text { fuels data along with numerical inputs to fire behavior, fire effects, and dynamic } \\
\text { vegetation models. } \\
\text { www.fs.fed.us/pnw/fera/fccs/index.shtml }\end{array}$ \\
\hline FEPS & $\begin{array}{l}\text { The Fire Emission Production Simulator (FEPS) manages data concerning } \\
\text { consumption, emissions, and heat release characteristics of prescribed burns and } \\
\text { wildland fires. } \\
\text { www.fs.fed.us/pnw/fera/feps/index.shtml }\end{array}$ \\
\hline FireFamilyPlus & $\begin{array}{l}\text { FireFamilyPlus analyzes and summarizes an integrated database of fire weather and fire } \\
\text { occurrence. It combines the functionality of the programs PCFIRDAT, PCSEASON, } \\
\text { FIRES, and CLIMATOLOGY. FFP can be used to calculate fire danger rating indices } \\
\text { and components and to summarize both fire and weather data. It offers options for } \\
\text { jointly analyzing fire and weather data. } \\
\text { www.firelab.org/project/firefamilyplus }\end{array}$ \\
\hline FlamMap & $\begin{array}{l}\text { FlamMap is a fire behavior mapping and analysis program that computes potential fire } \\
\text { behavior characteristics (such as spread rate, flame length, and fireline intensity) over } \\
\text { an entire landscape for constant weather and fuel moisture conditions. } \\
\text { www.firemodels.org/index.php/national-systems/flammap }\end{array}$ \\
\hline FOFEM & $\begin{array}{l}\text { FOFEM (First Order Fire Effects Model) is a computer program for predicting tree } \\
\text { mortality, fuel consumption, smoke production, and mineral soil exposure caused by } \\
\text { prescribed fire or wildfire. FOFEM provides quantitative fire effects information for } \\
\text { tree mortality, fuel consumption, mineral soil exposure, smoke, and soil heating. } \\
\text { www.firelab.org/project/fofem }\end{array}$ \\
\hline MTT & $\begin{array}{l}\text { FlamMap's Minimum Travel Time (MTT) is a two-dimensional fire growth model that } \\
\text { calculates fire growth and behavior by searching for the set of pathways with minimum } \\
\text { spread times from a point, line, or polygon ignition source, keeping environmental (fuel } \\
\text { moistures and winds) conditions constant for the duration of the simulation. } \\
\text { www.firelab.org/project/flammap }\end{array}$ \\
\hline RANDIG & $\begin{array}{l}\text { RANDIG simulates fire spread using the minimum travel time methods and inputs on } \\
\text { wind, fuel moisture, and topography. }\end{array}$ \\
\hline
\end{tabular}

3. The Risk Assessment Workflow provides a first-approximation probabilistic risk assessment for fuels treatment planning.

4. The Fuels Treatment Workflow simulates fuels treatment placement within an area of interest and simulates post-treatment influences on fire behavior and fire effects potentials.
5. The Prescribed Burn Planning Workflow provides the information needed to plan and document a proposed prescribed fire.

The following subsections provide an overview of each of these workflows as implemented in IFTDSS 2.0. Data acquisition and preparation are integrated into each workflow. 


\section{Hazard Analysis Workflow}

The Hazard Analysis Workflow provides tools for performing a current-condition assessment of fire hazard within an area of interest (Figure 1). This workflow allows users to spatially identify high fire hazard locations within an area of interest. Within IFTDSS, "fire hazard" is defined as an act or phenomenon with the potential to do harm (National Research Council 1989, Keane et al. 2010). Fire hazard in this context is expressed as potential fire behavior (e.g., flame length, rate of spread, fireline intensity), which is related to fuel properties within the area of interest and has the potential to harm values such as natural resources or human habitations within a landscape (Keane et al. 2010).

Fire hazard analysis can be viewed as an initial step in the fuels treatment and prescribed burn planning processes; it can be performed across many geographic scales (e.g., national, district, watershed). Once high fire hazard has been identified, planners can use additional tools within IFTDSS to conduct further analyses, such as identifying values at risk within the landscape or determining where to place fuel treatments to mitigate high fire hazard.

IFTDSS provides four modules available for use in the Hazard Analysis Workflow:

1. The IFT-FlamMap module computes potential fire behavior potentials across a user-defined landscape using a constant weather scenario and spatial landscape data from LANDFIRE data sets. The IFT-FlamMap uses the FlamMap 3.0 (Finney 2006) algorithms to simulate potential head fire behavior characteristics such as flame length, rate of

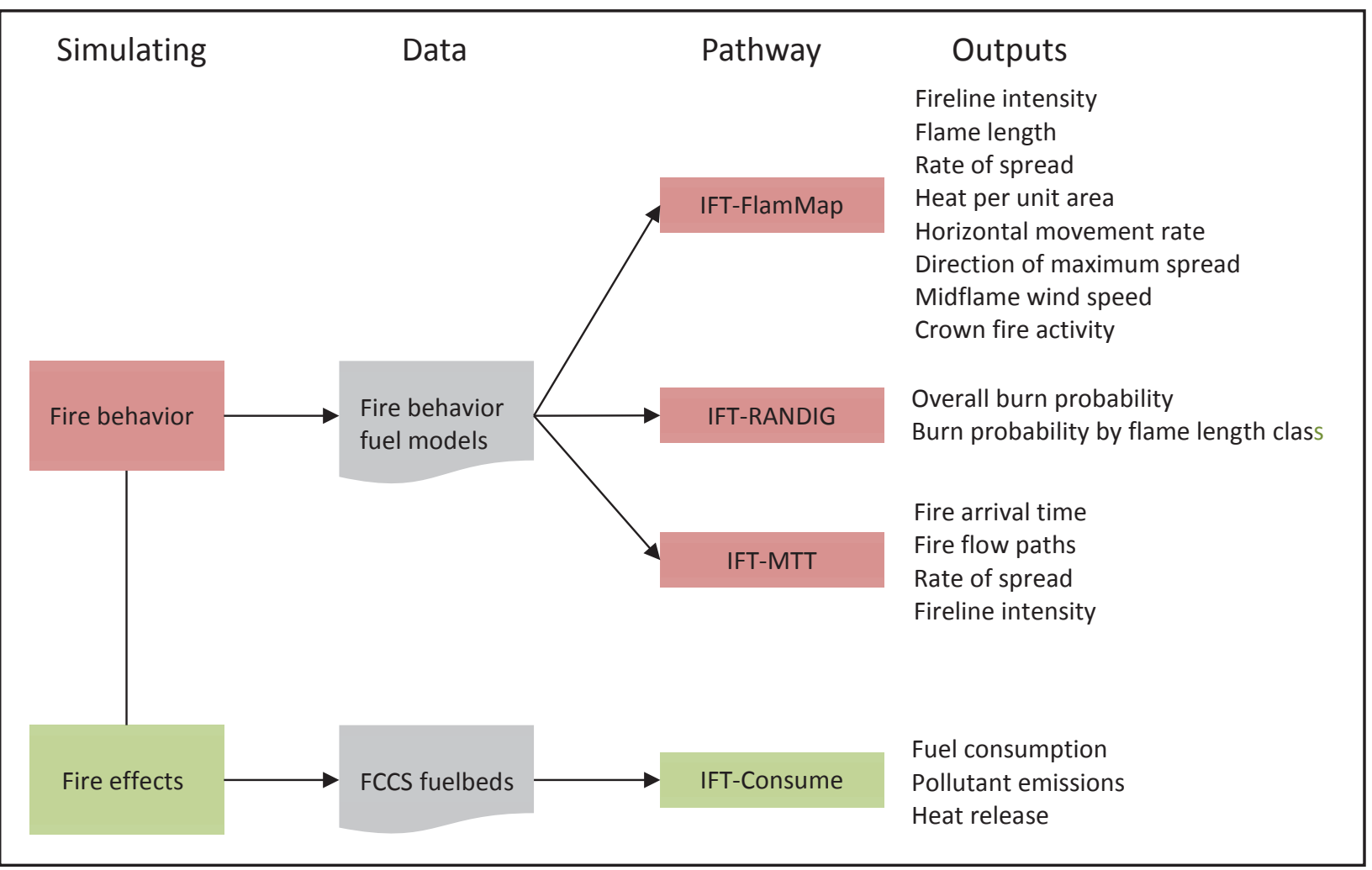

Figure 1. Overview of the Hazard Analysis Workflow. In the Hazard Analysis Workflow, fire behavior and fire effects models are used to simulate the potential harm or benefits due to fire on the landscape. The model outputs are used to evaluate whether fuels treatments are needed within an area of interest. 
spread, and fire line intensity in a spatial context.

2. The IFT-MTT module simulates fire growth, building on the functionality found in IFT-FlamMap. In this module, fire growth is simulated using the MTT algorithms (Finney 2002) and LANDFIRE data sets to provide spatial landscape data and a constant weather scenario.

3. The IFT-RANDIG module simulates burn probability potentials across a user-defined landscape. The IFT-RANDIG uses the MTT algorithms from the IFT-MTT module run numerous times across the landscape of interest (Finney 2002). Burn probability is produced by simulating a user-defined number of randomly located ignitions within the area of interest and recording the number of pixels that burn for each ignition. The probability that a pixel is burned, given a random ignition within the landscape, is calculated by dividing the number of times an individual pixel burns by the number of random ignitions. This module generates burn probability maps that represent the composite burn probability (burn probabilities for all flame lengths) and the probability that a pixel will burn with a specified flame length.

4. The IFT-Consume landscape module simulates fire effects (fuel consumption, smoke emissions, heat release) across an area of interest. Spatial outputs such as fuel consumption are computed for each pixel using a single fuel moisture scenario and the Fuel Characteristics Classification System (FCCS) fuelbed map from LANDFIRE as data inputs.

Each of these four modules produces digital maps that represent the current fuels on the ground and show how these fuels might burn under specified wind and pixel-specific environmental constraints. These digital maps provide useful information to support decisions on where to place fuels treatments based on potential fire behavior and fire effects.

\section{Risk Assessment Workflow}

There is no universally accepted framework for assessing the social, economic, and ecological risks resulting from fire in the landscape. However, recent work by Scott et al. (2013) has made progress towards that goal. In IFTDSS, we use the conditional probability concept described by Scott et al. (2013) to develop a risk assessment process that can be used to provide information to prioritize where fuels treatments may be used to mitigate fire hazard and risk. IFTDSS provides two approaches for assessing fire hazard and risk across the landscape based on the methods described in Calkin et al. (2010).

The conditional risk assessment processes proposed by Calkin et al. (2010) and modified for use in IFTDSS are designed to develop a strategic-level, first approximation of how fire likelihood and fire behavior potentials across landscapes influence risk to social, economic, and ecological values within an area of interest. The Calkin et al. (2010) approach provides a quantitative risk framework that approximates the expected loss and potential ecological benefits to values at risk from wildfire. In this process, fire simulation modules are used to estimate burn probabilities and fire behavior potentials. The modeled output is coupled with data on human and ecological values at risk, using fire-effects response functions to estimate the expected loss or potential benefit resulting from fire.

In IFTDSS, there are two approaches for assessing risk: a worst-case scenario in which the entire landscape is assumed to burn by head fire, and a flame length burn probability scenario in which fires are assumed to burn as head fires, backing fires, and flanking fires. 
Risk assessment by worst-case flame length. In this module, risk is defined as the expected net value change within an area calculated as the product of (a) the probability that the area represented by the pixel will burn given a random ignition within the project area, and (b) the resulting change in financial or ecological value (response function) if the area represented by the pixel burns with a specific flame length.

This method uses the response functions developed by Calkin et al. (2010), in conjunction with modeled flame lengths from the FlamMap fire behavior module and burn probabilities from the IFT-RANDIG burn probability simulator, to estimate the likelihood that the area represented by the pixel will burn, and the potential consequences if the area represented by the pixel is burned by a head fire.

This approach is referred to as the "worst case" estimation of fire risk because it is based on a single IFT-FlamMap run, in which the areas represented by every pixel are all always assumed to burn under the worst case (i.e., by a head fire). However, for this approach, the IFT-FlamMap-RANDIG burn probability simulator provides information as to whether the area represented by a pixel will burn regardless of flame length; that is, the area represented by a pixel can be burned as a backing fire, flanking fire, or head fire in the IFT-FlamMap-RANDIG simulations. This approach may overestimate the degree of damage to the value at risk in an area represented by an individual pixel, as all pixels are assumed to burn as a head fire.

Risk assessment by flame length burn probabilities. In this module, risk is defined as the expected net value change within an area calculated as the product of (a) the probabilities that the area represented by the pixel will burn (using user-defined flame lengths and flame length classes - low, medium, high, and very high) given a random ignition within the project area, and (b) the resulting change in finan- cial or ecological value (response function) if the area represented by the pixel burns for each user-defined flame length class.

This method uses the response functions developed by Calkin et al. (2010) and modeled flame length burn probabilities from the IFT-FlamMap-RANDIG burn probability simulator to estimate the likelihood of the area represented by the pixel burning, and the potential consequences if the area represented by the pixel is burned by a backing fire, a flanking fire, or a head fire.

This approach differs from the worst-case flame length approach in that it considers the likelihood of a fire burning as a backing fire, a flanking fire, or a head fire given a random ignition in the landscape when determining the potential losses or benefits for an area represented by a pixel burning. This approach likely produces more realistic modeled outcomes but is more complicated, more difficult to interpret the outcomes, and more difficult to explain the model results to others.

Products of the risk assessment modules. The products from each of the risk assessment models are a series of digital maps that provide information regarding where the fire is likely to burn given a random ignition, the potential hazard if the area burns, and the potential losses and benefits to values within the landscape if the area burns (Figure 2). The results from the risk assessment tools in IFTDSS can provide information useful for evaluating and prioritizing where to place fuel treatments to reduce fire hazard and risk to valued resources.

\section{Fuels Treatment Workflow}

Fuels treatments are designed to lower hazardous fire behavior potentials and restore ecosystem resiliency temporally and spatially (Agee and Skinner 2005, Martinson and Omi 2013). The goals of the Fuels Treatment Workflow in IFTDSS are to identify where fuels treatments may have the greatest influence 


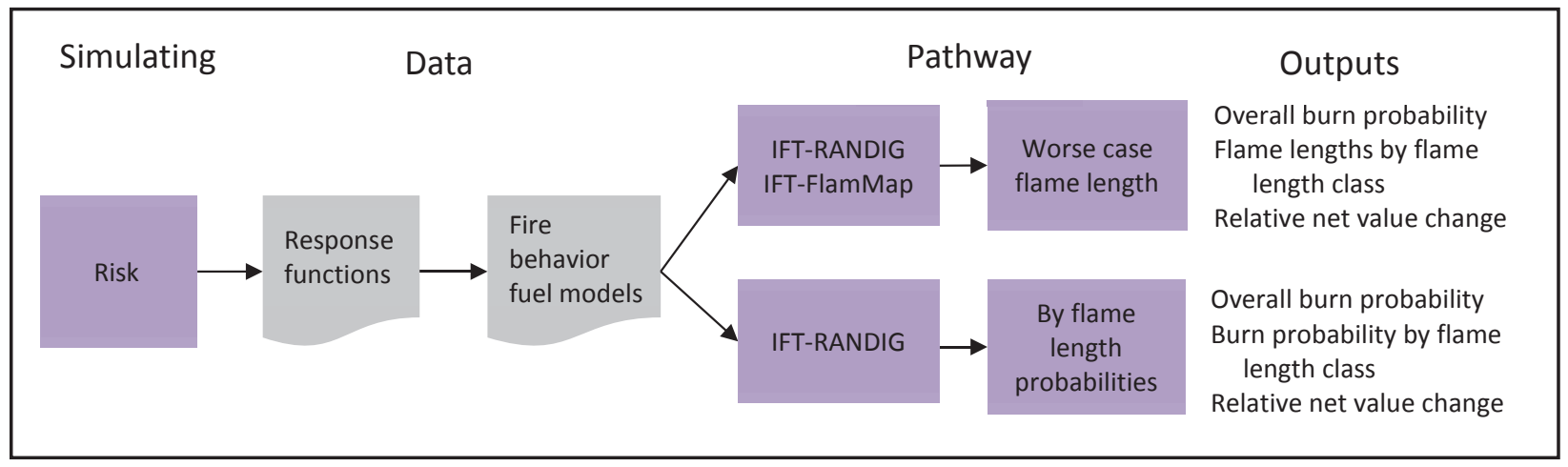

Figure 2. Overview of the Risk Assessment Workflow. In this workflow, users can spatially locate values at risk, assign functions to quantify the potential loss or benefits of burning, and spatially identify the location of the greatest potential harm to values at risk in an area of interest.

for mitigating wildland fire at the stand and landscape scale and to investigate the potential effectiveness of fuels treatments across spatial scales (Figure 3).

Fuels treatment across a landscape pathway. Using the fuels treatment across a landscape pathway, users can spatially assess where to locate fuels treatments and evaluate how effective a fuels treatment is at mitigating fire behavior potentials in a spatial context. In IFTDSS Version 2.0, users can simulate fuels treatments in a landscape by manually drawing polygons that cover the proposed fuels treatment area. Treatments are simulated by manually editing a LANDFIRE .lcp file with a set of editing tools. With these editing tools, users can change values (fuel model, canopy height, canopy base height, canopy bulk density, canopy coverage) for individual pixels within the fuels treatment polygon; the module then alters the individual pixels within the polygon to reflect the value changes and simulate how the proposed treatment would change the fuels on the landscape. Spatial fire behavior modules such as IFT-FlamMap and IFTMTT are then run across the untreated and the treated landscape to compare possible effects of treating the fuels on subsequent fire behavior. IFTDSS produces digital maps of difference and percentage difference that identify where change has occurred with the landscape.

\section{Prescribed Burn Planning Workflow}

Prescribed burns are planned to meet management and operational objectives in accordance with the Interagency Prescribed Fire Planning and Implementation Procedures Guide (National Wildfire Coordinating Group 2014). All prescribed burns must be conducted according to an approved plan. The guide provides a template for a prescribed fire burn plan, which is the legal document that provides an agency administrator with the information needed to approve a prescribed fire. The size and complexity of a prescribed fire project determine the level of effort and detail to be included in the plan; however, each plan must specifically address 21 standard elements in the prescribed fire template. IFTDSS integrates the April 2014 prescribed burn template and allows users to complete the burn plan template online. Once completed, the burn plan can be generated as a formatted burn plan in an editable Microsoft Word format.

Prescribed burn planning requires a burn planner to collect data, run fire behavior and fire effects simulations over a range of environmental variables, and make decisions that enable the burn plan objectives to be met during the process of maintaining control of the fire. To complete these tasks, prescribed burn planners typically use a variety of software tools with various data requirements. In 


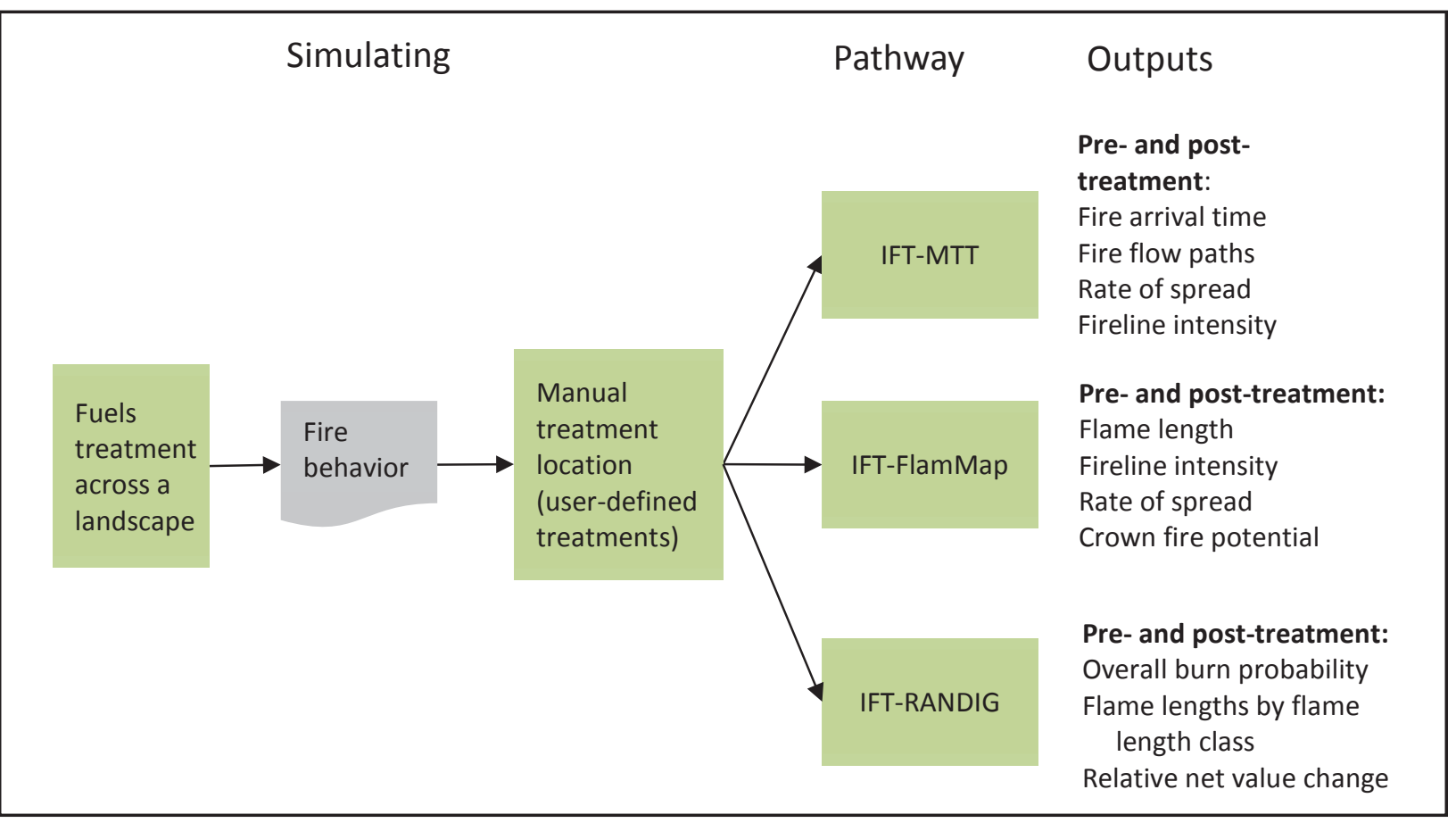

Figure 3. Overview of the fuels treatment workflow. In this workflow, IFTDSS users can model fire behavior and fire effects before and after simulating the application of fuels treatments. Pre- and post-fire comparisons of the model outputs provide decision support information to help identify the best locations for applying fuels treatments.

IFTDSS, model use and data structures have been simplified to streamline the prescribed burn planning process. Modeled output of fire behavior and fire effects is provided in a concise, user-friendly format that can be easily exported to Microsoft Word and Excel.

\section{IFTDSS modules that support prescribed} burn planning. IFTDSS provides several fire behavior modules that are useful for prescribed burn planning. These modules include the following:

1. The IFT-Surface module uses the algorithms and recreates the common fire behavior attributes (such as rate of spread and flame length) found in the SURFACE module of the standalone fire behavior prediction system BehavePlus (Heinsch and Andrews 2010).

2. The IFT-Crown is another aspatial fire behavior module that uses BehavePlus algorithms to simulate potential crown fire behavior on a single point within a landscape (Heinsch and Andrews 2010).

3. The IFT-Surface+Size module links the algorithms used in the BehavePlus SURFACE and SIZE modules to link fire behavior and fire size simulations (Heinsch and Andrews 2010).

4. The IFT-FlamMap Point module uses the algorithms in the FlamMap desktop software to model fire behavior at the individual stand level. The IFT-FlamMap Point module differs from IFT-Surface in that IFT-FlamMap Point links the algorithms for modeling surface fire behavior to the algorithms for modeling crown fire behavior through the use of a surface-to-crown fire transition algorithm (Scott and Reinhardt 2001). 
5. The IFT-FCCS Surface fire behavior module provides an alternative methodology for simulating potential fire behavior characteristics using a mathematical reworking of Rothermel's original fire spread model (Sandberg et al. 2007). The IFT-FCCS Surface fire behavior module uses FCCS fuelbed information (Ottmar et al. 2007), coupled with the reformulated version of the Rothermel fire spread model, to estimate fire behavior characteristics such as flame length, rate of spread, and fireline intensity.

6. The IFT-FlamMap module is the spatial fire behavior prediction module used for prescribed burn planning in Version 2.0. The IFT-FlamMap module computes fire behavior potentials across a user-defined landscape using a constant weather scenario and spatial landscape data from LANDFIRE data sets. The IFT-FlamMap uses the FlamMap 3.0 algorithms (Finney 2006) to simulate potential head fire behavior characteristics such as flame length, rate of spread, and fireline intensity in a spatial context.

IFTDSS simulates potential fire effects by using IFT-FOFEM and IFT-Consume to predict fuel consumption, smoke emissions, and tree mortality.

1. The IFT-FOFEM module provides tools to simulate potential fuel consumption, smoke production, and tree mortality caused by prescribed fire or wildfire. In order to calculate consumption and emissions, cover type, fuel loading, and moisture information are needed. The output variables include amount of fuel consumed during fire, post-burn fuel loading, emissions released during flaming and smoldering combustion, and total flaming and smoldering time. In order to calculate tree mortality, tree species, stand characteristics, and fire behavior information are needed. The output variables include percent tree mortality, stand basal area pre- and post-fire, and stand canopy cover pre- and post-fire.

2. The IFT-Consume (Ottmar et al. 1993, Prichard et al. 2006) is a decision-support tool that uses realistic fuels data to assist with planning for prescribed burns and wildfires. IFT-Consume predicts fuel consumption, pollutant emissions, and heat release from input fuel characteristics, lighting patterns, fuel moistures, and other environmental variables.

The prescribed burn plan template. The modules in the prescribed burn planning workflow (Figure 4) can be used to obtain the information needed to address several of the prescribed burn plan elements (Table 2).

How Does IFTDSS Allow Fire Managers to Evaluate the Ecological Threat and Benefit of Fuels Treatments?

IFTDSS allows land managers to evaluate whether fuel treatment strategies designed to restore past ecosystem structure and function create the ecological conditions desired. Fuels treatments for ecological restoration are not always prudent and may not be appropriate for restoring fire regimes in certain ecosystems (Agee and Skinner 2005). By providing the capability of modeling fire behavior and fire effects before and after a planned treatment, IFTDSS allows land managers to identify whether a proposed treatment will result in making the forest more fire resilient (Agee and Skinner 2005). For example, if the potential for high tree mortality is not decreased by a proposed treatment, the treatment will not increase the resiliency of the stand; in such a case, either the fuels treatment is not appropri- 


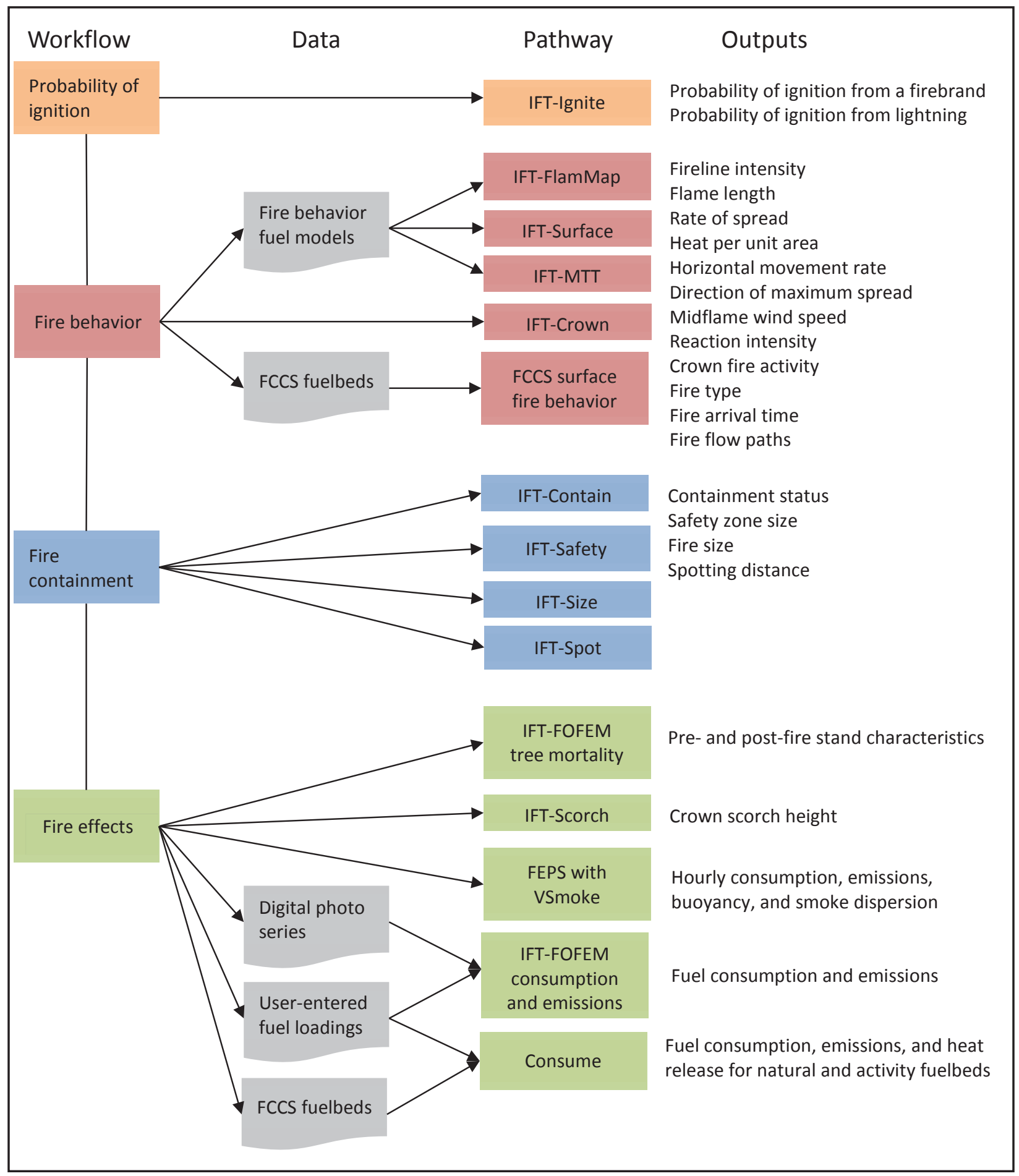

Figure 4. Overview of the prescribed burn workflow. IFTDSS provides direct access to the modeling tools and related information needed to write a burn plan. Within IFTDSS, users can model the fire behavior and fire effects outputs required to create a prescription, create vicinity and site maps, enter the outputs directly into an online template, and generate a formatted burn plan as a Microsoft Word document. 
Table 2. Standard prescribed burn plan elements and the tools available in IFTDSS to help complete each element. $\mathrm{o}=$ facilitates in decision making; $\bullet=$ outputs needed for burn plan; $\mathrm{m}=$ element information is manually entered in burn plan template or completed on day of burn.

\begin{tabular}{|c|c|c|c|c|c|c|c|c|c|c|c|c|c|c|c|c|c|c|c|}
\hline & \multicolumn{3}{|c|}{$\begin{array}{c}\text { Data and } \\
\text { mapping } \\
\text { tools }\end{array}$} & \multirow{2}{*}{ 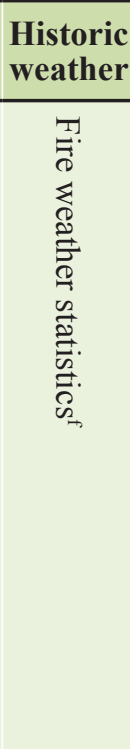 } & \multicolumn{2}{|c|}{ Ignition } & \multicolumn{4}{|c|}{$\begin{array}{c}\text { Contain- } \\
\text { ment }\end{array}$} & \multicolumn{4}{|c|}{ Effects } & \multicolumn{5}{|c|}{ Behavior } \\
\hline & 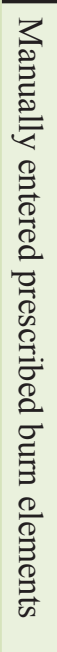 & 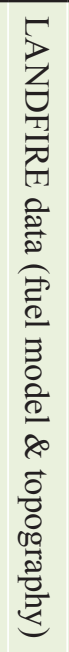 & 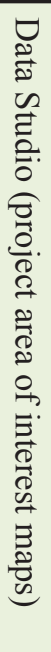 & & 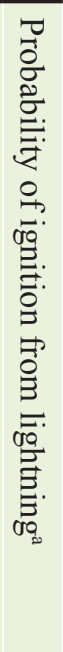 & 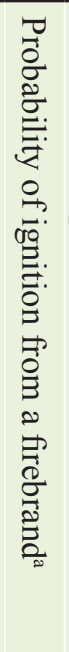 & 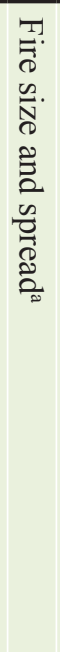 & 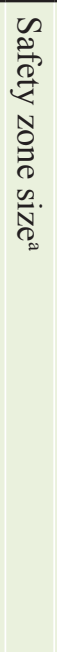 & 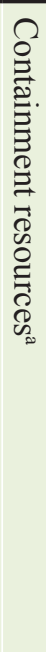 & 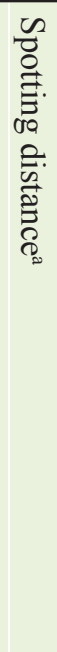 & 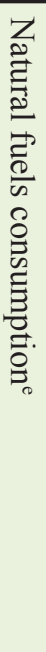 & 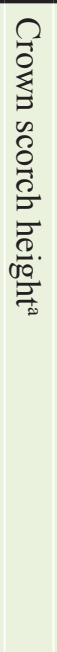 & 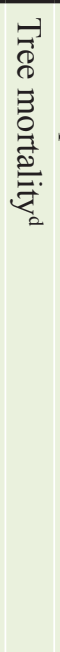 & 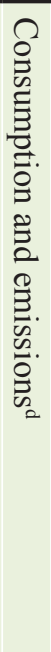 & $\begin{array}{l}T \\
\overrightarrow{0} \\
0 \\
0 \\
0 \\
0 \\
0 \\
0 \\
\vdots \\
0 \\
0 \\
\tilde{0} \\
0 \\
0 \\
0 \\
0 \\
0 \\
0 \\
0 \\
0 \\
0 \\
0 \\
0 \\
0 \\
0 \\
0\end{array}$ & 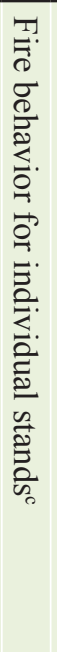 & 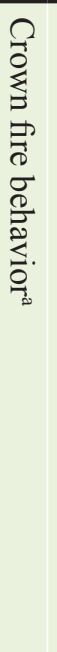 & 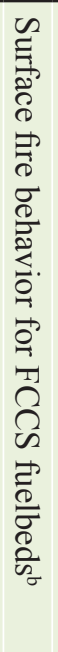 & 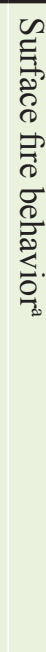 \\
\hline 1: Signature page & $\mathrm{m}$ & & & & & & & & & & & & & & & & & & \\
\hline 2: Agency go, no-go checklist & $\mathrm{m}$ & & & & & & & & & & & & & & & & & & \\
\hline 3: Complexity analysis summary & & & & 0 & o & o & o & o & o & $\mathrm{O}$ & o & o & o & o & $\mathrm{O}$ & $\mathrm{o}$ & o & o & o \\
\hline 4: Description of prescribed fire area & & $\bullet$ & $\bullet$ & & & & & & & & & & & & $\bullet$ & & & & \\
\hline 5: Objectives & & & & & & & & & & & o & 0 & $\mathrm{o}$ & o & 0 & o & o & $\mathrm{o}$ & o \\
\hline \multicolumn{20}{|l|}{ 6: Funding } \\
\hline 7: Prescription & & & & $\bullet$ & & $\bullet$ & & & & $\bullet$ & o & $\bullet$ & $\mathrm{o}$ & o & $\bullet$ & $\bullet$ & o & $\bullet$ & $\bullet$ \\
\hline 8: Scheduling & $\mathrm{m}$ & & & & & & & & & & & & & & & & & & \\
\hline 9: Pre-burn consideration, weather & & & & 0 & & & & & & & & & & & & & & & \\
\hline 10: Briefing checklist & $\mathrm{m}$ & & & & & & & & & & & & & & & & & & \\
\hline 11: Organization \& equipment & $\mathrm{m}$ & & & & & & & & & & & & & & & & & & \\
\hline 12: Communication & $\mathrm{m}$ & & & & & & & & & & & & & & & & & & \\
\hline 13: Public, personnel safety, medical & $\mathrm{m}$ & & & & & & & & & & & & & & & & & & \\
\hline 14: Test fire & $\mathrm{m}$ & & & & & & & & & & & & & & & & & & \\
\hline 15: Ignition plan & $\mathrm{m}$ & & & & & & & & & & & & & & & & & & o \\
\hline 16: Holding plan & & & $\mathrm{o}$ & & & o & o & & o & o & & & & & o & o & o & o & o \\
\hline 17: Contingency plan & & & & o & & o & o & o & o & o & & o & & $\mathrm{o}$ & o & o & o & o & o \\
\hline 18: Wildfire conversion & $\mathrm{m}$ & & & & & & & & & & & & & & & & & & \\
\hline 19: Smoke management & & & & o & & & & & & & $\bullet$ & & & $\bullet$ & & & & & \\
\hline 20: Monitoring & $\mathrm{m}$ & & & & & & & & & & & & & & & & & & \\
\hline 21: Post-burn activities & $\mathrm{m}$ & & & & & & & & & & & & & & & & & & \\
\hline Appendix A maps (vicinity, project) & $\bullet$ & $\bullet$ & & & & & & & & & & & & & $\bullet$ & & & & \\
\hline
\end{tabular}

${ }^{a}$ IFT-BehavePlus

${ }^{\mathrm{b}} \mathrm{FCCS}$

c IFT-FlamMap

${ }^{\mathrm{d}}$ IFT-FOFEM

${ }^{\mathrm{e}}$ Consume

${ }^{\mathrm{f}}$ IFT-FireFamilyPlus 
ate for mitigating fire behavior and effects or the vegetation type does not lend itself to ecological restoration using fuels treatments.

When fire managers use the Risk Assessment Workflow, the emergent property of using IFTDSS to model fire behavior and fire effects across landscapes is apparent: IFTDSS brings all the disparate tools and data together in one place, completes a complicated analysis, and allows the land manager to view the results as a cohesive whole in a digital landscape. IFTDSS provides a platform for users to view the interactions of the individual models and how these interactions influence the model predictions, in this case, a quantitative risk assessment. Prior to IFTDSS, fire managers could only do this in an ad hoc fashion and could not see how the output of one model directly influenced the final results in a modeling pathway. For example, when running a risk assessment within IFTDSS, a net value change is produced by multiplying burn probability, flame length, and a response function that represents the effect that burning will have on the land unit (Calkin et al. 2010). The net value change then represents whether the fire will have a negative or positive effect on the values at risk within the landscape. The values at risk can be resource based or ecologically based depending on how the response functions are set (Calkin et al. 2010). By running multiple simulations rapidly and efficiently in IFTDSS, land managers can test alternate strategies such as implementing fuels treatments to lower flame length or decrease burn probability and observe how that interaction potentially increases or decreases the harm or benefit to values at risk across the landscape.

\section{How Has IFTDSS Been Used?}

IFTDSS is still in beta, but we are aware of several cases in which IFTDSS has proved to efficiently model fire potentials and illustrate how the potentials may be changed by applying fuels treatments. Several groups in the
USDA Forest Service Pacific Northwest Region (Region 6) are using the Interagency Prescribed Burn Template functionality in IFTDSS to create and share their prescribed burn plans. A number of Bureau of Indian Affairs fire ecologists are using IFTDSS to assess what burning conditions will allow them to meet their prescription requirements on large landscape burns, and we understand that the Bureau of Land Management is evaluating IFTDSS to determine whether the system can be used to identify treatments that make greater sage grouse (Centrocercus urophasianus) habitat more fire resilient. Finally, Sonoma Technology, Inc. (Petaluma, California, USA), worked with FireSafe Monterey (Monterey, California, USA) to evaluate whether a set of proposed fuels treatments were located appropriately to mitigate future fire potential near the Ventana Wilderness, Los Padres National Forest, California, USA (http://www.sonomatech.com/project.cfm?uprojectid=1225).

\section{IFTDSS Limitations}

The primary limitation to IFTDSS is that it is an online system and requires Internet access to function. There are many positive aspects of an online system, such as the ability to locate multiple modeling tools in a single location; the ability to access multiple, highly variable datasets; and the avoidance of the need to load multiple software applications onto a user's desktop computer. The downside of that flexibility is that an Internet connection is required to access IFTDSS and the modeling tools and processes within the online system.

A second limitation is that, when using a chained modeling approach, errors in one model can be passed on to subsequent steps in a modeling framework (Keane et al. 2013, Drury et al. 2014, Hyde et al. 2015). Moreover, the transmission of errors in one model may be compounded when those outputs are used by other models in later steps (Drury et al. 2014). 
While it has not been tested specifically, we infer from these studies and our internal evaluations of IFTDSS that the biggest current uncertainty in the modeling framework occurs in the fuel model data input step. Each of these studies shows that large potential errors are found when comparing field data to the fuel model maps currently in use as fire model input (Keane et al. 2013, Drury et al. 2014, Hyde et al. 2015). In fact, Drury et al. (2014) found that the data input can result in as much as a factor of 3 difference and, as noted above, that the error could be transferred from one step to the next.

A third limitation may be a result of one of the most positive aspects of IFTDSS; that is, its ease of use. In workshops, arguments have been made that users need to be trained on the use of the data, tools, and processes within IFTDSS. It has been argued that IFTDSS may be too easy to use, that its ease of use may make it too easy to overlook problems with models and data, and that untrained or inexperienced IFTDSS users may not interpret the modeling results correctly.

\section{Future IFTDSS Development}

New functionality in IFTDSS will be driven by the business needs of fire, fuels, and resource managers. In the short term, IFTDSS developers plan to incorporate models and scientific algorithms that simulate temporal changes to fuels and vegetation. Fuels treatment planners need to be able to simulate how long a treatment will last; in other words, if a particular treatment is implemented, how long it is likely to effectively mitigate fire behavior and fire effects potentials. Initially, it is clear that common tools for modeling forest growth, such as the Forest Vegetation Simulator (FVS) and FVS extensions such as the Fire and Fuels Extension (FFE), will be integrated into IFTDSS (Reinhardt and Crookston 2003, Crookston and Dixon 2005). Initial research has begun on how to incorporate FVS into IFTDSS workflows; our analysis shows that integrating FVS-FFE will provide useful decision support for simulating fuels treatment and assessing the effectiveness of fuels treatments over time.

IFTDSS is not designed to be a static system. In fact, IFTDSS has been designed to accommodate long-term future needs that arise. The Scientific Modeling Framework (SMF) used to build IFTDSS (T. Lavezzo and others, Sonoma Technology, Inc., Petaluma, California, USA, unpublished data) will enable IFTDSS to evolve as fuels treatment planning needs evolve. The SMF was designed to be extendable, enabling the addition of new models and data sets as they become available without negatively influencing the structure and function of the current models and tools (T. Lavezzo and others, unpublished data). For example, as new and better risk assessment methods and outputs are developed, IFTDSS will be ready to incorporate them into existing workflows or to develop new workflows to rapidly put the best available science into practice for fuels treatment planning.

In addition, the flexibility of the SMF framework facilitates upgrading the current modeling tools as new versions and updates are made available. Plans are in place to provide model developers a "playground" or tool kit where they can add model upgrades, new versions of existing models, and new models. The model developer's tool kit will enable model developers to test their beta versions of fire behavior and fire effects tools within an IFTDSS environment. When the model developer indicates that the model is ready for full implementation, the new model, or an updated version of an existing model, will be sent to the IFTDSS advisory group. The advisory group will decide how and when these new versions of tools will be implemented into the operational version of IFTDSS.

Although IFTDSS has been designed to facilitate model comparisons (either model to model, or model outputs to field observations), there is no way to check the accuracy of model 
predictions within IFTDSS 2.0. Future functionality will allow users to simulate fire behavior or fire effects potentials and then use monitoring data to check and evaluate how well the modeling tools within IFTDSS predicted the actual outcomes of a fuels treatment or prescribed burn. The initial plan is to incorporate the Feat/Firemon Integrated (FFI; Lutes et al. 2009) monitoring data into IFTDSS to identify how the FFI monitoring data can be used to update model inputs and evaluate post-treatment model predictions. This will help provide insight into how the modeling tools within IFTDSS are performing and where the biggest uncertainties are within a fire behavior or fire effects modeling framework.

\section{CONCLUSIONS}

IFTDSS greatly decreases the time and energy required to model potential fuels treatment effects across multiple spatial scales. Users have noted that, by providing direct access to the data and models commonly used for fire management planning in a single location, IFTDSS reduces planning time from weeks or months to days, depending on the scope of the project; in fact, users have made comments during workshops such as, "I just did in 15 minutes what used to take me days to accomplish." Previously, fire planners would spend considerable time and energy determining what data sets were available and, once they acquired the data, might find that the data were not compatible with the fire behavior or fire effects models on their desktop computers. With IFTDSS, both data and models are available in intuitive, easy-to-use pathways that guide users through the process. IFTDSS removes the burden of getting the models to run and enables planners to spend more time and energy on analyzing whether the data inputs and model outputs capture the variability in the landscape, and how the data can be used to make landscape management decisions (such as when and how to use both planned and unplanned ignitions).

In that context, IFTDSS version 2.0 directly addresses the stated need for a means to manage the array of fire modeling software tools, models, and scientific algorithms developed for fire behavior, fire effects, and fuels treatment modeling by providing access to the tools within an organized, easy-to-use, online system of tools and data. IFTDSS framework and vision minimizes the software maze by centralizing the scientific models used when planning fuels treatments in a single location, eliminating the current status quo of fragmented, standalone tools and unconnected data sets. Many initial IFTDSS users have referred to IFTDSS as "one stop shopping" for simulating fuels treatments.

IFTDSS allows fuels treatment specialists and fire planners to use stand-level and spatial fire behavior and fire effects modeling techniques to evaluate which sections of a specific landscape are at hazard to burn more severely (Figure 5a); they can simulate the areas within the landscape that are more likely to burn (Figure 5b); they can simulate potential fire paths across a landscape (Figure 5c); and, ultimately, they can locate fuels treatments and evaluate how the fuels treatments may alter fire behavior and fire effects in subsequent wildfires across a range of fire weather and fuel moisture scenarios (Figure 5d). The system encourages critical thinking as users now have the tools to test various fire behavior, fire effects, or fire management scenarios within a feasible time frame and single user interface. In essence, IFTDSS provides a unique framework for evaluating the available options for locating fuels treatments, determining what treatments to apply, and conveying the reasons for applying fuels treatments to public stakeholders. 


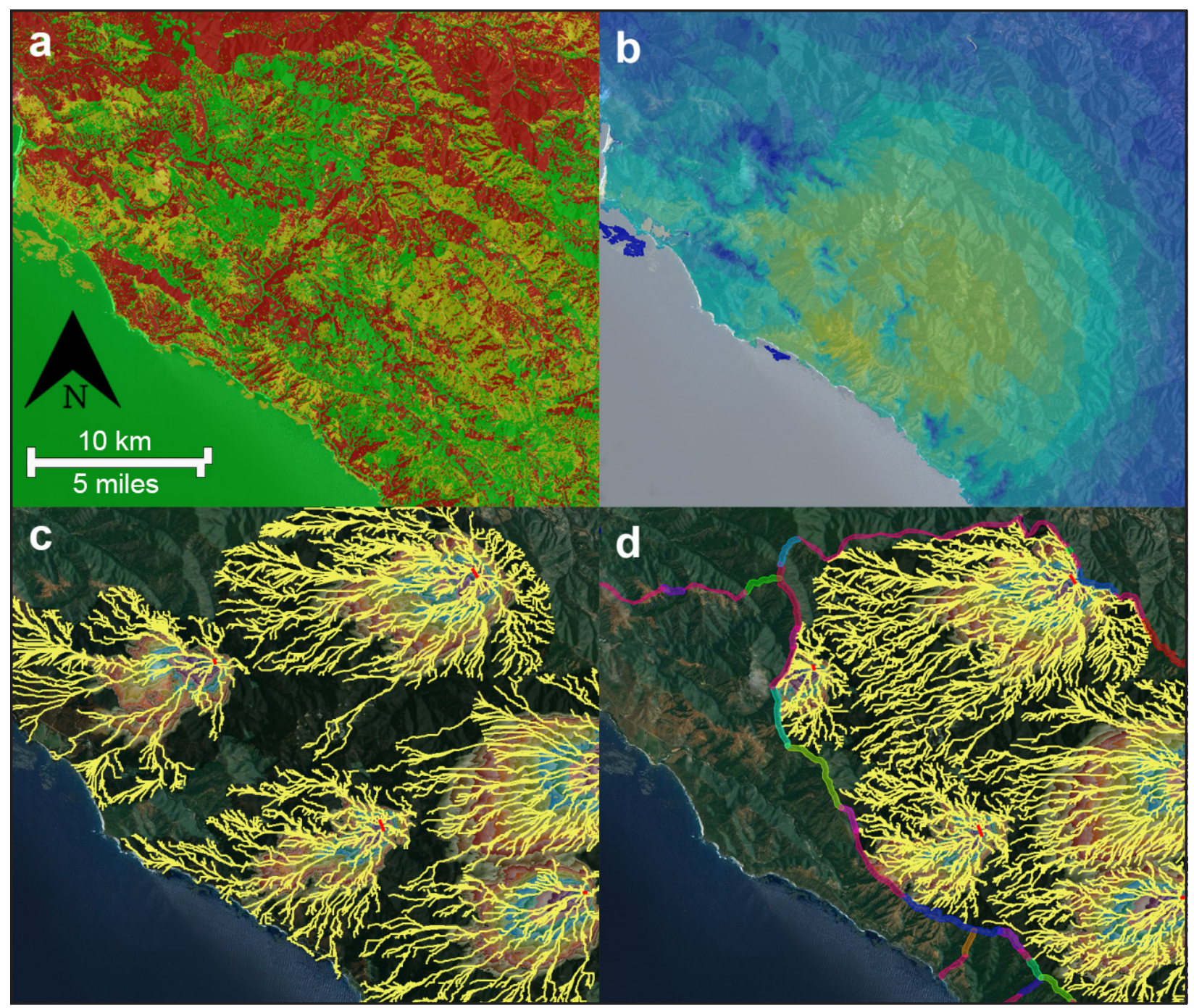

Figure 5. Four types of fire behavior simulation. Panel (a) shows an IFT-FlamMap basic run where each pixel within an area of interest is simulated to burn as a head fire with a single fuel moisture and wind profile. Mapped here is flame length output under dry moisture conditions. Flame length categories are preset by the user and are typically expressed in feet; in this example, green indicates low flame lengths $(0 \mathrm{~m}$ to $1.2 \mathrm{~m} ; 0 \mathrm{ft}$ to $4 \mathrm{ft})$, yellow indicates medium flame lengths $(1.2 \mathrm{~m}$ to $2.4 \mathrm{~m} ; 4 \mathrm{ft}$ to $8 \mathrm{ft})$, orange indicates high flame lengths $(2.4 \mathrm{~m}$ to $3.4 \mathrm{~m} ; 8 \mathrm{ft}$ to $11 \mathrm{ft})$, and red indicates very high flame lengths $(>3.4 \mathrm{~m} ;>11$ $\mathrm{ft}$ ). Panel (b) shows IFT-RANDIG burn probability output that provides indices of the likelihood of burning throughout the area given a random ignition. Burn probabilities in this example range from low ( $1 \%$ to $5 \%$; dark blue) to high (55\% to $60 \%$; yellow). Panel (c) shows time for fire to arrive and pre-treatment potential fire paths across an area of interest, and panel (d) shows the influence of fuels treatment (brightly colored fuel break polygons) on restricting fire movement across the same landscape. The simulations in panel (c) and (d) were conducted using the same environmental conditions; the only change is the addition of the fuels treatments to the simulation. 


\section{ACKNOWLEDGEMENTS}

It is impossible to list all the people who have made contributions to the success of IFTDSS. However, we would like to thank all the fire planners and fuels specialists who have provided useful comments at each stage of the design and development. Currently there are 582 registered users within IFTDSS, but smaller groups have contributed significantly over the past five years. Forty-nine fuels specialists provided insight into their planning process for conducting fuels treatment planning, the models they used for planning, the models they would like to use, and why they were not using those models. The original group of eight (a small group of fire behavior, fire effects, and fuels managers) reviewed the original concept papers and contributed comments regarding the business needs and tasks that were delivered to Sonoma Technology, Inc., by the National Wildfire Coordinating Group Fuels Treatment Working Group. A series of increasingly larger groups reviewed the initial mockups and workflow concept documents for validity and utility for planning fuels treatments. Finally, many potential users provided very useful feedback through the website links, or through personal interviews, webinars, face-to-face workshops, and the Software Engineering Institute evaluation workshops. IFTDSS could not have been built without the input of these individuals. We would also like to thank the fire science modeling and tool developer community for producing and graciously providing the tools and products we used in IFTDSS. In closing, we would like to thank B. Jenison, T. Swedberg, and N. Benson of the JFSP for their never-ending support. A special thanks to J. Cissel of the JFSP for his perseverance, support, and leadership.

\section{LITERATURE CITED}

Agee, J.K., and C.N. Skinner. 2005. Basic principles of forest fuel reduction treatments. Forest Ecology and Management 211: 83-96. doi: 10.1016/j.foreco.2005.01.034

Bennett, C.M., N. Brown, D. Doney, L.P. Gates, S. Miller, M.S. Palmquist, and P. Place. 2013. Final report of the Interagency Fuels Treatment Decision Support System (IFTDSS) evaluation study. Special Report CMU/SEI-2013-SR-017, Software Engineering Institute, Carnegie Mellon University, Pittsburgh, Pennsylvania, USA.

Berry, A.H., G. Donovan, and H. Hesseln. 2006. Prescribed burning costs and the WUI: economic effects in the Pacific Northwest. Western Journal of Applied Forestry 21: 72-78.

Blanchard, B., and R.L. Ryan. 2007. Managing the wildland-urban interface in the Northeast: perceptions of fire risk and hazard reduction strategies. Northern Journal of Applied Forestry 24(3): 203-208.

Calkin, D.E., A.A. Ager, J. Gilbertson-Day, J.H. Scott, M.A. Finney, C. Schrader-Patton, T.M. Quigley, J.R. Strittholt, and J.D. Kaiden. 2010. Wildfire risk and hazard: procedures for the first approximation. USDA Forest Service General Technical Report RMRS-GTR-235, Rocky Mountain Research Station, Fort Collins, Colorado, USA. [Available at http://www. fs.fed.us/rm/pubs/rmrs_gtr235.pdf]

Countryman, C.M. 2004. Forecasting wildland fire behavior: aids and guides. Fire Management Today 64(1): 49-52.

Crookston, N.L., and G.E. Dixon. 2005. The forest vegetation simulator: a review of its structure, content, and applications. Computers and Electronics in Agriculture 49: 60-80. doi: 10.1016/j.compag.2005.02.003 
Dennison, P.E., S.C. Brewer, J.D. Arnold, and M.A. Moritz. 2014. Large wildfire trends in the western United States, 1984-2011. Geophysical Research Letters 41: 2928-2933. doi: 10.1002/2014GL059576

Drury, S.A., N.K Larkin, T.T. Strand, S. Huang, S.J. Strenfel, E.M. Banwell, T.E. O’Brien, and S.M. Raffuse. 2014. Intercomparison of fire size, fuel loading, fuel consumption, and smoke emissions estimates on the 2006 Tripod Fire, Washington, USA. Fire Ecology 10(1): 56-83. doi: 10.4996/fireecology.1001056

Finney, M.A. 2002. Fire growth using minimum travel time methods. Canadian Journal of Forest Research 32: 1420-1424. doi: 10.1139/x02-068

Finney, M.A. 2006. An overview of FlamMap fire modeling capabilities. Pages 213-220 in: P.L. Andrews and B.W. Butler, editors. Fuels management - how to measure success. USDA Forest Service Proceedings RMRS-P-41, Rocky Mountain Research Station, Fort Collins, Colorado, USA. [Available at http://www.fs.fed.us/rm/pubs/rmrs_p041/rmrs_p041_213_220. pdf]

Fulé, P.Z., J.E. Crouse, J.P. Roccaforte, and E.L. Kalies. 2012. Do thinning and/or burning treatments in western USA ponderosa or Jeffrey pine-dominated forests help restore natural fire behavior? Forest Ecology and Management 269: 68-81. doi: 10.1016/j.foreco.2011.12.025

Funk, T.H. 2009. Interagency Fuels Treatment Decision Support System conceptual design. Sonoma Technology, Inc., Petaluma, California, USA.

Heinsch, F.A., and P.L. Andrews. 2010. BehavePlus fire modeling system, version 5.0: design and features. USDA Forest Service General Technical Report RMRS-GTR-249, Rocky Mountain Research Station, Fort Collins, Colorado, USA. [Available at http://www.fs.fed.us/ rm/pubs/rmrs_gtr249.pdf]

Hyde, J., E.K. Strand, A.T. Hudak, and D. Hamilton. 2015. A case study comparison of LANDFIRE fuel loading and emissions generation on a mixed conifer forest in northern Idaho, USA. Fire Ecology 11(3): 108-127. doi: 10.4996/fireecology.1103108.

Keane, R.E., S.A. Drury, E. Karau, P.F. Hessburg, and K.M. Reynolds. 2010. A method for mapping fire hazard and risk across multiple scales and its application in fire management. Ecological Modelling 221: 2-18. doi: 10.1016/j.ecolmodel.2008.10.022

Keane, R.E., J.M. Herynk, C. Toney, S.P. Urbanski, D.C. Lutes, and R.D. Ottmar. 2013. Evaluating the performance and mapping of three fuel classification systems using Forest Inventory and Analysis surface fuel measurements. Forest Ecology and Management 305: 248-263. doi: 10.1016/j.foreco.2013.06.001

Lutes, D.C., N.C. Benson, M. Keifer, J.F. Caratti, and S.A. Streetman. 2009. FFI: a software tool for ecological monitoring. International Journal of Wildland Fire 18: 310-314. doi: 10.1071/ WF08083

Martinson, E.J., and P.N. Omi. 2013. Fuel treatments and fire severity: a meta-analysis. USDA Forest Service Research Paper RMRS-RP-103WWW, Rocky Mountain Research Station, Fort Collins, Colorado, USA. [Available at http://www.fs.fed.us/rm/pubs/rmrs_rp103.pdf]

Miller, J., H. Safford, M. Crimmins, and A. Thode. 2009. Quantitative evidence for increasing forest fire severity in the Sierra Nevada and southern Cascade Mountains, California and Nevada, USA. Ecosystems 12(1): 16-32. doi: 10.1007/s10021-008-9201-9

National Research Council. 1989. Improving risk communication. National Academy Press, Washington, D.C., USA. [Available at http://www.nap.edu/openbook.php?isbn=0309039436]

National Wildfire Coordinating Group. 2014. Interagency prescribed fire planning and implementation procedures guide. National Wildfire Coordinating Group Report PMS 484, Boise, Idaho, USA. [Available at http://www.nwcg.gov/pms/RxFire/pms484.pdf] 
Ottmar, R.D., M.F. Burns, J.N. Hall, and A.D. Hanson. 1993. Consume users guide, version 1.0. USDA Forest Service General Technical Report PNW-GTR-304, Pacific Northwest Research Station, Seattle, Washington, USA. [Available at http://www.fs.fed.us/pnw/pubs/pnw_gtr304. pdf]

Ottmar, R.D., D.V. Sandberg, C.L. Riccardi, and S.J. Prichard. 2007. An overview of the fuel characteristic classification system: quantifying, classifying, and creating fuelbeds for resource planning. Canadian Journal of Forest Research 37: 2383-2393. doi: 10.1139/X07-077

Prichard, S.L., R.D. Ottmar, and G.K. Anderson. 2006. Consume 3.0 user's guide. USDA Forest Service, Pacific Northwest Research Station, Seattle, Washington. [Available at http:// www.fs.fed.us/pnw/fera/research/smoke/consume/consume30_users_guide.pdf]

Radeloff, V.C., R.B. Hammer, S.I. Stewart, J.S. Fried, S.S. Holcomb, and J.F. McKeefry. 2005. The wildland-urban interface in the United States. Ecological Applications 15: 799-805. doi: 10.1890/04-1413

Rauscher, H.M., J. Cissel, E.C. Christiansen, T.L. Haste, S.A. Drury, N.J.M. Wheeler, D.J. Noha, L. Chinkin, C.M. Bennett, N. Brown, D. Doney, L.P. Gates, S. Miller, M.S. Palmquist, P.R.H. Place, and K. Ernstrom. 2013. The Interagency Fuels Treatment Decision Support System project: final report. Rauscher Enterprises, Leicester, North Carolina, USA.

Reinhardt, E., and N.L Crookston. 2003. The fire and fuels extension to the Forest Vegetation Simulator. USDA Forest Service General Technical Report RMRS-GTR-116, Rocky Mountain Research Station, Fort Collins, Colorado, USA. [Available at http://www.fs.fed.us/rm/ pubs/rmrs_gtr116.pdf]

Reinhardt, E.D., R. Keane, D.E. Calkin, and J.D. Cohen. 2008. Objectives and considerations for wildland fuel treatment in forested ecosystems of the interior western United States. Forest Ecology and Management 256: 1997-2006. doi: 10.1016/j.foreco.2008.09.016

Sandberg, D.V., C.L. Riccardi, and M.D. Schaaf. 2007. Reformulation of Rothermel's wildland fire behaviour model for heterogeneous fuelbeds. Canadian Journal of Forest Research 37: 2438-2455. doi: 10.1139/X07-094

Scott, J.H., and E.D. Reinhardt. 2001. Assessing crown fire potential by linking models of surface and crown fire behavior. USDA Forest Service Research Paper RMRS-RP-29, Rocky Mountain Research Station, Fort Collins, Colorado, USA.

Scott, J.H., M.P. Thompson, and D.E. Calkin. 2013. A wildfire risk assessment framework for land and resource management. USDA Forest Service General Technical Report RMRSGTR-315, Rocky Mountain Research Station, Fort Collins, Colorado, USA.

US Congress. 1998. Forest Recovery and Protection Act of 1998, Report on HR 2515, House Report 105-440, part 1. 105th Congress, second session, March 12, Washington, D.C., USA.

US Government Accounting Office. 1999. Western national forests: a cohesive strategy is needed to address catastrophic wildfire threats. GAO/RCED-99-65, Government Accounting Office, Washington, D.C., USA.

US Government Accounting Office. 2002. Severe wildland fires: leadership and accountability needed to reduce risks to communities and resources. GAO-02-259, Government Accounting Office, Washington, D.C., USA.

US Government Accounting Office. 2003. Additional actions required to better identify and prioritize lands needing fuels reduction. GAO-03-805, Government Accounting Office, Washington, D.C., USA.

US Government Accounting Office. 2004 Forest Service and BLM need better information and a systematic approach for assessing risks of environmental effects. GAO-04-705, Government Accounting Office, Washington, D.C., USA. 
van Mantgem, P.J., J.C.B. Nesmith, M. Keifer, E.E. Knapp, A. Flint, and L. Flint. 2013. Climatic stress increases forest fire severity across the western United States. Ecology Letters 16: 1151-1156. doi: 10.1111/ele.12151

Westerling, A.L., H.G. Hidalgo, D.R. Cayan, and T.W. Swetnam. 2006. Warming and earlier spring increase western US forest wildfire activity. Science 313(5789): 940-943. doi: 10.1126/science. 1128834 